\title{
Aromatic compounds produced by endophytic fungi isolated from red alga Asparagopsis taxiformis - Falkenbergia stage
}

Rebeca P. Medina, Angela R. Araujo, Raymond J. Andersen, Marcos A. Soares, Fabio de A. Silva \& Dulce H. S. Silva

To cite this article: Rebeca P. Medina, Angela R. Araujo, Raymond J. Andersen, Marcos A. Soares, Fabio de A. Silva \& Dulce H. S. Silva (2019) Aromatic compounds produced by endophytic fungi isolated from red alga Asparagopsis taxiformis - Falkenbergia stage, Natural Product Research, 33:3, 443-446, DOI: 10.1080/14786419.2018.1455037

To link to this article: https://doi.org/10.1080/14786419.2018.1455037

View supplementary material ¿

Published online: 26 Mar 2018.

Submit your article to this journal 주

山 Article views: 106

View Crossmark data $\nearrow$ 


\title{
Aromatic compounds produced by endophytic fungi isolated from red alga Asparagopsis taxiformis - Falkenbergia stage
}

\author{
Rebeca P. Medinaa , Angela R. Araujo ${ }^{a}$, Raymond J. Andersen ${ }^{b}$, Marcos A. Soaresc, \\ Fabio de A. Silvac and Dulce H. S. Silva ${ }^{a}$ iD
}

aNúcleo de Bioensaios, Biossíntese e Ecofisiologia de Produtos Naturais (NuBBE), Departamento de Química Orgânica, Instituto de Química, UNESP - Univ. Estadual Paulista, Araraquara, Brazil; bepartment of Chemistry and Department of Earth, Ocean and Atmospheric Sciences, University of British Columbia, Vancouver, Canada; ' Instituto de Biociências, Universidade Federal de Mato Grosso, Cuiabá, Brazil

\begin{abstract}
Endophytic fungi were isolated from red alga Asparagopsis taxiformis - Falkenbergia stage, collected from the Brazilian coast, and were identified as Annulohypoxylon stygium (AT-03) and A. yungensis (AT06 ) based on their macro/micromorphological and molecular features. Bioassay-guided fractionation of the EtOAc extract from laboratory cultures of both strains yielded known compounds pyrogallol from A. stygium, (3R)-scytalone and $(3 R, 4 R)-4$-hydroxy-scytalone from $A$. yungensis. Pyrogallol was active against methicillin-resistant Staphylococcus aureus (MRSA) and Escherichia coli strains. An inactive fraction from A. stygium afforded two additional compounds, $(3 R, 4 R)$ 3,4,5-trihydroxy-1-tetralone and tyrosol. Optically active compounds had their stereochemistry determined by circular dichroism (CD) spectroscopy.
\end{abstract}

\section{ARTICLE HISTORY}

Received 24 August 2017

Accepted 11 March 2018

\section{KEYWORDS}

Marine red alga; Asparagopsis taxiformis; endophytic fungus; Annulohypoxylon; antimicrobial activity; aromatic compounds 


\section{Introduction}

Recent studies on marine-derived endophytic microorganisms existing in distinct habitats have demonstrated their potential as a source of new pharmacologically active substances with a marked chemodiversity (Flewelling et al. 2015).

Endophytic fungi from red algae have shown a diversity of bioactive compounds such as antimicrobial curvularin-type macrolides (Dai et al. 2010) and cytotoxic polyketides (Gao et al. 2011). In this context, our work describes the isolation and identification of metabolites from fungal strains isolated from red alga Asparagopsis taxiformis (diploid phase), guided by antimicrobial assays.

\section{Results and discussion}

After fractionation of crude extracts from each strain (AT-03 - A. stygium and AT-06 - A. yungensis), the fractions and crude extracts were tested for antimicrobial activity. The samples tested were inactive against Pseudomonas aeruginosa, Bacillus subtilis and Candida albicans. However, fractions AT-03-F8, AT-06-F8 and AT-06-F9 were active against $E$. coli with inhibition zone diameters $\left(\Phi_{i}\right)$ of 2,2 and $6 \mathrm{~mm}$ at $40 \mu \mathrm{g} /$ disk, respectively. Fractions AT-03-F8 and AT-06-F9 were also active against MRSA ( $\Phi_{i} 2$ and $3 \mathrm{~mm}$ at $40 \mu \mathrm{g} /$ disk, respectively). The positive controls polymyxin B (30 $\mathrm{gg} /$ disk for $E$. coli) and rifamycin (10 $\mu \mathrm{g} /$ disk for MRSA) presented $\Phi_{i} 15$ and $3 \mathrm{~mm}$, respectively.

Purification of fractions with antimicrobial activity using reversed-phase HPLC led to isolation of compounds 1-3 (Figure 1). Their structures were elucidated from NMR, MS and CD experiments and comparison with data in the literature. Compound $\mathbf{1}$ was identified as pyrogallol. Its ${ }^{1} \mathrm{H}$ NMR spectrum (Figure S2) showed a double doublet at $\delta 6.40\left(J_{5-4} 7.8 ; J_{5-6}\right.$ $7.8 \mathrm{~Hz} ; 1 \mathrm{H} ; \mathrm{H}-5)$ and a doublet at $\delta 6.23\left(J_{4-5} 7.8 ; 2 \mathrm{H} ; \mathrm{H}-4 / \mathrm{H}-6\right)$.<smiles>Oc1cccc(O)c1O</smiles>

1<smiles>O=C1CC(O)Cc2cc(O)cc(O)c21</smiles>

2<smiles>O=C1C[C@@H](O)[C@H](O)c2cc(O)cc(O)c21</smiles>

3<smiles>O=C1C[C@H](O)[C@H](O)c2c(O)cccc21</smiles>

4<smiles>OCCc1ccc(O)cc1</smiles>

Figure 1. Isolated compounds from A. stygium (1, 4 and 5 ) and A. yungensis (2 and 3). 
Compounds 2 and $\mathbf{3}$ were identified as scytalone (Li et al. 2012) and 4-hydroxy-scytalone (Gremaud and Tabacchi 1996), respectively. Their absolute configurations were established by $C D$ spectroscopy. The CD spectrum of scytalone (2) (Figure S4) indicated a (3R)configuration ( $\lambda_{\text {ext }} 311 \mathrm{~nm}, \Delta \varepsilon+0.65$ ) (Husain et al. 2014). The CD spectrum of compound 3 showed positive and negative Cotton effects at 279 and $214 \mathrm{~nm}$, respectively (Figure S7), indicating a (4R)- configuration. A positive Cotton effect at $321 \mathrm{~nm}$ and the coupling constant $\left(J_{3-4} 7.2 \mathrm{~Hz}\right.$ ) in the ${ }^{1} \mathrm{H}$ NMR spectrum (Figure S8), indicated a trans relative configuration for $\mathrm{H}-3 / \mathrm{H}-4$ (Bringmann et al. 2001).

Compounds 1-3 were also tested for antimicrobial activity. Pyrogallol was active against MRSA and $E$. coli $\left(\Phi_{i} 4\right.$ and $3 \mathrm{~mm}$ at $40 \mu \mathrm{g} /$ disk, respectively), whereas compounds $\mathbf{2}$ and $\mathbf{3}$ were inactive against both strains.

The inactive fraction AT-03-F5 was purified using reversed-phase HPLC and afforded 3,4,5-trihydroxy-1-tetralone (4) (Fujimoto et al. 1986) and tyrosol (5) (Chu et al. 2014) (Figure 1). The CD spectrum of compound $\mathbf{4}$ (Figure S10) was similar to that of compound $\mathbf{3}$ and evidenced (3R)- and (4R)- configurations (Bringmann et al. 2001).

Tetralone derivatives $\mathbf{2 - 4}$ could be regarded as chemotaxonomic markers as they have been considered intermediates or side products in 1,8-dihydroxynaphthalene (DHN) type melanin biosynthesis in fungal sources (Wheeler et al. 2008). In addition, chemotaxonomy has been a key tool in delimiting species within Annulohypoxylon, especially in recently identified $A$. yugensis (Kuhnert et al. 2016). Thus the isolation of these compounds from the studied strains indicates the DHN melanin-type biosynthetic pathway is active in such microorganisms.

\section{Conclusion}

This is the first report on endophytic fungi from the red alga A. taxiformis, and the identification of $A$. stygium and $A$. yungensis as its endophytes. The isolation of compounds $\mathbf{1}-\mathbf{5}$ contributes to the chemotaxonomy of the Annulohypoxylon genus and expands knowledge on the chemodiversity of marine natural products from Brazilian biomes.

\section{Supplementary material}

Experimental details and spectroscopic data are available online.

\section{Disclosure statement}

No potential conflict of interest was reported by the authors.

\section{Funding}

We acknowledge CAPES for a scholarship to R. P. M. (\#3334/15-5), CNPq (\#474270/2012-2) and FAPESP (\#13/07600-3) for financial support.

\section{ORCID}

Dulce H. S. Silva (D) http://orcid.org/0000-0002-1516-7765 


\section{References}

Bringmann G, Messer K, Saeb W, Peters E, Peters K. 2001. The absolute configuration of (+)-isoshinanolone and in situ LC-CD analysis of its stereoisomers from crude extracts. Phytochemistry. 56:387-391.

Chu YH, Chen CJ, Wu SH, Hsieh JF. 2014. Inhibition of xanthine oxidase by rhodiola crenulata extracts and their phytochemicals. J Agric Food Chem. 62:3742-3749.

Dai J, Krohn K, Flörke U, Pescitelli G, Kerti G, Papp T, Kövér KE, Bényei AC, Draeger S, Schulz B, et al. 2010. Curvularin-type metabolites from the fungus Curvularia sp. isolated from a marine alga. Eur J Org Chem. 2010:6928-6937.

Flewelling AJ, Currie J, Gray CA, Johnson JA. 2015. Endophytes from marine macroalgae: promising sources of novel natural products. Curr Sci. 109:88-111.

Fujimoto Y, Yokoyama E, Takahashi T, Uzawa J, Morooka N, Tsunoda H, Tatsuno T. 1986. Studies on the metabolites of Penicillium diversum var. aureum. I Chem Pharm Bull. 34:1497-1500.

Gao S, Li XM, Du F, Li C, Proksch P, Wang BG. 2011. Secondary metabolites from a marine-derived endophytic fungus Penicillium chrysogenum QEN-24S. Mar Drugs. 9:59-70.

Gremaud G, Tabacchi R. 1996. Relationship between the fungus Ceratocystis fimbriata coffea and the canker disease of the coffee tree. Phytochemistry. 42:1547-1549.

Husain SM, Schätzle MA, Lüdeke S, Müller M. 2014. Unprecedented role of hydronaphthoquinone tautomers in biosynthesis. Angew Chem, Int Ed. 53:9806-9811.

Kuhnert E, Sir E, Lambert C, Hyde K, Hladki A, Romero A, Rohde M, Stadler, S.. 2016. Phylogenetic and chemotaxonomic resolution of the genus Annulohypoxylon (Xylariaceae) including four new species. Fungal Divers. 85:1-43.

Li XJ, Gao JM, Chen H, Zhang AL, Tang M. 2012. Toxins from a symbiotic fungus, Leptographium qinlingensis associated with Dendroctonus armandi and their in vitro toxicities to Pinus armandi seedlings. Eur J Plant Pathol. 134:239-247.

Wheeler MH, Abramczyk D, Puckhaber LS, Naruse M, Ebizuka Y, Fujii I, Szaniszlo PJ. 2008. New biosynthetic step in the melanin pathway of Wangiella (Exophiala) dermatitidis: evidence for 2-Acetyl1,3,6,8-tetrahydroxynaphthalene as a novel precursor. Eukaryot Cell. 7:1699-1711. 